\title{
PERCEPÇÃO DOS DISCENTES SOBRE AULA PRÁTICA NO ENSINO DE QUÍMICA COMO POTENCIALIZADORA DA TEORIA ${ }^{1}$
}

\author{
Allanny kelly de Sousa ${ }^{2}$, Universidade Federal de Campina Grande (UFCG), \\ allanny.cz@gmail.com \\ Maricélia Lucena Ferreira ${ }^{3}$, Universidade Federal de Campina Grande (UFCG), \\ mluc_cena@hotmail.com
}

\begin{abstract}
RESUMO
A presente pesquisa objetiva investigar e relatar a percepção dos discentes de uma escola de ensino médio do município de Cajazeiras, no Estado da Paraíba, sobre a relevância da aplicação de aulas práticas no ensino de Química, bem como pontos importantes para estes relativos à didática, metodologia, avaliação, entre outros, que possam vir a contribuir com a qualidade do ensino de Química. O estudo foi realizado com 66 alunos do $1^{\circ}$ ao $3^{\circ}$ ano do ensino médio, através da aplicação de um questionário, onde os dados coletados foram tratados de forma qualitativa e quantitativa e expostos através de gráficos. Num panorama geral, o resultado evidencia o quanto os discentes estão e se sentem atraídos por aulas diferenciadas da somente tradicional teoria, onde se pode observar nas questões ênfase deste estudo, um percentual de $94 \%$ dos estudantes gostaria de mais aulas práticas de Química e 56\% destes discentes sugerem mais aulas práticas no ensino de Química como melhoria no ensino da disciplina em sua instituição.
\end{abstract}

PALAVRAS-CHAVE: Aula Prática; Ensino de Química; Experimentação; Pesquisa.

\section{STUDENTS PERCEPTION ABOUT PRACTICAL LESSONS IN CEMISTRY TEACHING AS A POTENTIZATION OF THE THEORY}

\begin{abstract}
This research has the objective investigate and report the perception of students from a school of the municipality of Cajazeiras, in the state of Paraíba in Brazil, about the relevance of the application of practical lessons in chemistry teaching, as well as important points for these related to didactics, methodology, evaluation, among others, that can contribute with the quality of chemistry teaching. The study was conducted with 66 students from first to third year of high school, through the application of a questionnaire, where the collected data were treated in a qualitative and quantitative manner and exposed through graphs. In a general panorama, the result demonstrates how much the differences are and are attracted to differentiated lessons from the only traditional theory, where you can observe the emphasis on the questions of this study, a percentage of $94 \%$ of students would like more lessons in
\end{abstract}

\footnotetext{
${ }^{1} \mathrm{O}$ presente trabalho não contou com apoio financeiro de nenhuma natureza para sua realização.

${ }^{2}$ Granduanda Licenciatura em Química- UFCG

${ }^{3}$ Granduanda Licenciatura em Química- UFCG
}

Revista de Pesquisa Interdisciplinar, Cajazeiras, n. 2, suplementar, p. 476-491, set. de 2017. 
chemistry practice and 56\% of these students suggest more practical lessons in chemistry teaching as an improvement in teaching discipline in his institution.

KEYWORDS: Practical lessons; Teaching chemistry; Experimentation; Research.

\section{LA PERCEPCIÓN DE LOS ESTUDIANTES DE LECCIONES PRÁCTICAS EN LA ENSEÑANZA DE LA QUÍMICA COMO UNA POTENCIACIÓN DE}

\section{LA TEORÍA}

\section{RESUMEN}

Esta investigación pretende investigar y reportar la percepción de los recuentos de una escuela secundaria de Brasil, en el estado de Paraíba, sobre la pertinencia de la aplicación de lecciones prácticas en la enseñanza de la química, así como puntos importantes para estos relacionados con la didáctica, la metodología, la evaluación, entre otros, que pueden contribuir a la calidad de la enseñanza de la química. El estudio se llevó a cabo con 66 alumnos de $1^{\circ}$ a $3^{\circ}$ año da escuela secundaria, mediante la aplicación de un cuestionario, donde los datos recabados fueron tratados de forma cualitativa y cuantitativa y expuestos a través de gráficas. En un panorama general, el resultado demuestra lo mucho que son las diferencias y se sienten atraídos por lecciones diferenciadas de la única teoría tradicional, donde se puede observar en el énfasis de este estudio, un porcentaje del $94 \%$ de los estudiantes desea más lecciones de química y el $56 \%$ de estos puntos sugieren lecciones más prácticas en la enseñanza de la química como una mejora en la enseñanza de la disciplina en su institución.

PALABRAS CLAVES: Lecciones prácticas; Enseñanza de la química; Experimentación; Investigación.

\section{INTRODUÇÃO}

$\mathrm{Na}$ atualidade, como o crescente desenvolvimento tecnológico, a sociedade vivencia um ritmo elevado de informações que nem sempre são devidamente tratadas. Diante deste fato, cabe à escola a responsabilidade de atender a essa demanda dos cidadãos em formação. Nesse sentido, o profissional docente torna-se o mediador na transformação de uma mera informação em conhecimento cognitivo, impulsionando os discentes a aprimorarem o conhecimento técnico/científico com o desenvolvimento de habilidades que envolvam uma base contextualizada e que também possa ocorrer de forma interdisciplinar, para promover um ensino eficiente e expressivo. 
Corriqueiramente o livro didático é a única ferramenta educacional a qual os educadores empregam para organizar as ideias e articular a exposição destas aos alunos, porém, o professor da atualidade não deve se deter a utilizar apenas este recurso didático.

No ensino de Química, em particular, percebe-se muitas vezes que o aluno não consegue associar o conteúdo estudado com o seu cotidiano, o que na maioria das vezes o faz desinteressar-se pela disciplina. Isto pode ser indício de um ensino descontextualizado, ou seja, desconexo à realidade do educando, devendo o professor mostra-se apto para atuar nos novos moldes de ensino e de aprendizagem que requer essa nova sociedade aldeada de informações e tecnologias. Conforme citado no PCN+ para o ensino de Química:

A Química pode ser um instrumento da formação humana que amplia os horizontes culturais e a autonomia no exercício da cidadania, se o conhecimento químico for promovido como um dos meios de interpretar o mundo e intervir na realidade, se for apresentado como ciência, com seus conceitos, métodos e linguagens próprios, e como construção histórica, relacionada ao desenvolvimento tecnológico e aos muitos aspectos da vida em sociedade. (PCN+, 2002, p. 84)

Sendo assim, quando o aluno está envolvido no processo de aprendizagem, ou simplesmente quando ele é autor e protagonista na construção do próprio conhecimento, a Química terá um peso de contribuição mais condizente e coerente com a realidade deste.

Diante do exposto, a presente pesquisa objetiva investigar o ensino de Química na Escola Estadual de Ensino Técnico Cristiano Cartaxo no município de Cajazeiras, no Estado da Paraíba, pela percepção dos discentes. Levantando pontos importantes para estes relativos à didática, metodologia, avaliação, entre outros, que possam vir a contribuir com a qualidade do ensino de Química.

\section{MÉTODOS ALIADOS NO ENSINO DE QUÍMICA}

Uma metodologia que pode (e deve) unir teoria ao cotidiano é a experimentação. Colocar os alunos à frente de situações as quais a química é a protagonista da solução, agrega valores nem sempre percebidos na teorização do assunto. Guimarães (2009, P. 198) afirma que "a experimentação pode ser uma estratégia eficiente para a criação de problemas reais que 
permitam a contextualização e o estímulo de questionamentos de investigação", sendo o experimento uma base onde o discente possa articular possibilidades de soluções.

Outro processo aliado do ensino de Química é realização de pesquisas em sala de aula, pois facilitam o processo de ensino e aprendizagem, envolve professor e aluno, forma cidadãos mais críticos com perfil de pesquisador, bem como auxilia na exploração das habilidades ou capacidades dos discentes. Além disso, vale salientar que as aulas se tornam mais atrativas e divertidas, os alunos não tentam diminuir o tempo de aula e ainda aprimoram o conhecimento teórico adquirido. $\mathrm{O}$ desenvolvimento de pesquisas envolvendo professor e aluno desenvolve o senso criativo e construtivo e incentiva no aluno a leitura e o diálogo crítico e constante.

Enveredando pelo mundo da tecnologia, o uso de simuladores educacionais, encontrados facilmente em plataformas digitais educacionais gratuitas, é além de um atrativo para essa nova clientela educacional, bem como um bom aliado. O uso de jogos eletrônicos e simuladores desperta o interesse do discente para a Química de forma lúdica e ao mesmo tempo eficiente para a aprendizagem.

Destes métodos descritos, a ênfase que daremos a este estudo é para a aula experimental, pois devido a Química tratar de assuntos na maioria das vezes abstratos, impalpáveis, é bem melhor visualizar propriamente dito como se desencadeiam as transformações (reações) químicas e depois inferir os devidos conceitos. Ferreira, Silva e Sales (2015, pág. 2), apontam que:

A indisponibilidade do material e local próprio para experimentação explicaria o motivo pelo qual os professores frequentemente preferem as aulas tradicionais ou práticas de demonstração ao invés de atividades nas quais os estudantes manipulam os experimentos sob sua orientação. Mesmo quando eles têm acesso ao material, a quantidade é insuficiente para que todos os alunos possam manusear.

Mas existem diversos estudos na literatura que demonstram a aplicação de aulas práticas através de materiais alternativos, dispostos no dia a dia dos alunos e com baixo custo de aquisição, ressaltando dessa forma a Química no cotidiano do discente.

\section{METODOLOGIA}


Desenvolveu-se esta pesquisa de campo na Escola Estadual de Ensino Técnico Cristiano Cartaxo na cidade de Cajazeiras-PB, o qual inicialmente foi elaborado e aplicado um questionário sobre o ensino de Química no ensino médio a alunos da supracitada instituição de ensino.

O questionário contendo oito indagações foi aplicado num unirveso de 66 alunos do $1^{\circ}, 2^{\circ}$ e $3^{\circ}$ ano do ensino médio, sendo 22 alunos por turma, que se dispuseram em participar do estudo de forma voluntária. O questionário prima por identificar desde a importância que os alunos atribuem à Química para a sua formação e até que fatores poderiam contribuir ou prejudicar na aprendizagem da disciplina.

\section{QUESTIONÁRIO APLICADO AOS ALUNOS}

$\rightarrow 1^{\circ}$ ano do ensino médio: (22 ALUNOS)

1) O que você acha da disciplina de Química?

Interessante: 11 alunos

Ótima: 2 alunos

Boa: 5 alunos

Regular: 4 alunos

Chata: nenhum aluno

2) Qual o principal método de avaliação do professor de Química?

Provas: 4 alunos

Trabalhos individuais: 14 alunos

Por trabalhos coletivos: 4 alunos

3) Se você tivesse que avaliar seu professor, em relação a sua forma de ensinar, qual seria a sua nota?

7,0: 2 alunos

8,0: 6 alunos

9,0: 6 alunos 
10,0: 8 alunos

4) Qual o tipo de aula utilizada pelo professor?

Expositiva: 1 aluno

Experimental: 1 aluno

Discursiva: 15 alunos

Participativa: 5 alunos

5) A sua compreensão do conteúdo após a explicação do professor?

Excelente: nenhum aluno

Ótima: 3 alunos

Boa: 12 alunos

Regular: 7 alunos

Ruim: nenhum aluno

6) Com relação à aula prática com que frequência o professor utiliza?

Sempre: 2 alunos

Às vezes: 6 alunos

Raramente: 14 alunos

7) Você gostaria que houvesse mais aula prática?

Sim: 20 alunos

Não: 2 alunos

8) Deixe uma sugestão para a melhoria do ensino de química na instituição de ensino:

Didática: 3 alunos

Metodologia: 4 alunos

Aulas práticas: 13 alunos

Recursos tecnológicos: 1 aluno

Mais aulas de Química: 1 aluno 
$\rightarrow 2^{\circ}$ ano do ensino médio: (22 ALUNOS)

1) O que você acha da disciplina de Química:

Interessante: 8 alunos

Ótima: 3 alunos

Boa: 8 alunos

Regular: 3 alunos

Chata: nenhum aluno

2) Qual o principal método de avaliação do professor de Química?

Provas: 7 alunos

Trabalhos individuais: 12 alunos

Por trabalhos coletivos: 3 alunos

3) Se você tivesse que avaliar seu professor, em relação a sua forma de ensinar, qual seria a sua nota?

7,0: nenhum aluno

8,0: 6 alunos

9,0: 5 alunos

10,0: 11 alunos

4) Qual o tipo de aula utilizada pelo professor?

Expositiva: 2 alunos

Experimental: nenhum aluno

Discursiva: 15 alunos

Participativa: 5 alunos

5) A sua compreensão do conteúdo após a explicação do professor?

Excelente: nenhum aluno

Ótima: 6 alunos

Boa: 10 alunos

Regular: 4 alunos 
Ruim: 2 alunos

6) Com relação à aula prática com que frequência o professor utiliza?

Sempre: nenhum aluno

às vezes: 8 alunos

Raramente: 14 alunos

7) Você gostaria que houvesse mais aula prática?

Sim: 20 alunos

Não: 2 alunos

8) Deixe uma sugestão para a melhoria do ensino de química na instituição de ensino:

Didática: 3 alunos

Metodologia: 2 alunos

Aulas práticas: 13 alunos

Recursos tecnológicos: 3 alunos

Mais aulas de Química: 1 aluno

$\rightarrow 3^{\circ}$ ano do ensino médio: (22 ALUNOS)

1) O que você acha da disciplina de Química:

Interessante: 7 alunos

Ótima: 3 alunos

Boa: 5 alunos

Regular: 5 alunos

Chata: 2 alunos

2) Qual o principal método de avaliação do professor de Química?

Provas: 13 alunos

Trabalhos individuais: 3 alunos

Por trabalhos coletivos: 6 alunos 


\section{PROPEX}

3) Se você tivesse que avaliar seu professor, em relação a sua forma de ensinar, qual seria a sua nota?

7,0: 1 aluno

8,0: 2 alunos

9,0: 9 alunos

10,0: 10 alunos

4) Qual o tipo de aula utilizada pelo professor?

Expositiva: 1 aluno

Experimental: 1 aluno

Discursiva: 15 alunos

Participativa: 5 alunos

5) A sua compreensão do conteúdo após a explicação do professor?

Excelente: 1 aluno

Ótima: 8 alunos

Boa: 4 alunos

Regular: 8 alunos

Ruim: 1 aluno

6) Com relação à aula prática com que frequência o professor utiliza?

Sempre: 2 alunos

às vezes: 6 alunos

Raramente: 14 alunos

7) Você gostaria que houvesse mais aula prática?

Sim: 22 alunos

Não: nenhum aluno

8) Deixe uma sugestão para a melhoria do ensino de química na instituição de ensino:

Didática: 2 alunos

Revista de Pesquisa Interdisciplinar, Cajazeiras, n. 2, suplementar, p. 476-491, set. de 2017. 
Metodologia: 4 alunos

Aulas práticas: 11 alunos

Recursos tecnológicos: 2 alunos

Mais aulas de Química: 3 alunos

Após a análise quantitativa dos dados obtidos no questionário, fez-se o tratamento percentual e lançaram-se os mesmos nos gráficos ilustrativos.

\section{RESULTADOS E DISCUSSÕES}

Para análise dos dados coletados, fez-se o percentual do universo dos 66 discentes, ou seja, o somatório das três turmas de 22 alunos pesquisados e registraram-se os mesmos em forma de gráficos para uma melhor ilustração dos resultados obtidos.

Na $1^{\text {a }}$ questão, Gráfico 01, quando perguntados sobre o que acha da disciplina de química, $40 \%$ dos alunos responderam como sendo uma disciplina interessante, $27 \%$ considerou uma disciplina regular, $18 \%$ considera uma ótima disciplina, $12 \%$ destes consideram como sendo boa disciplina, enquanto que 3\% acham uma disciplina chata.

Gráfico 01 - Opinião em relação a disciplina de Química.

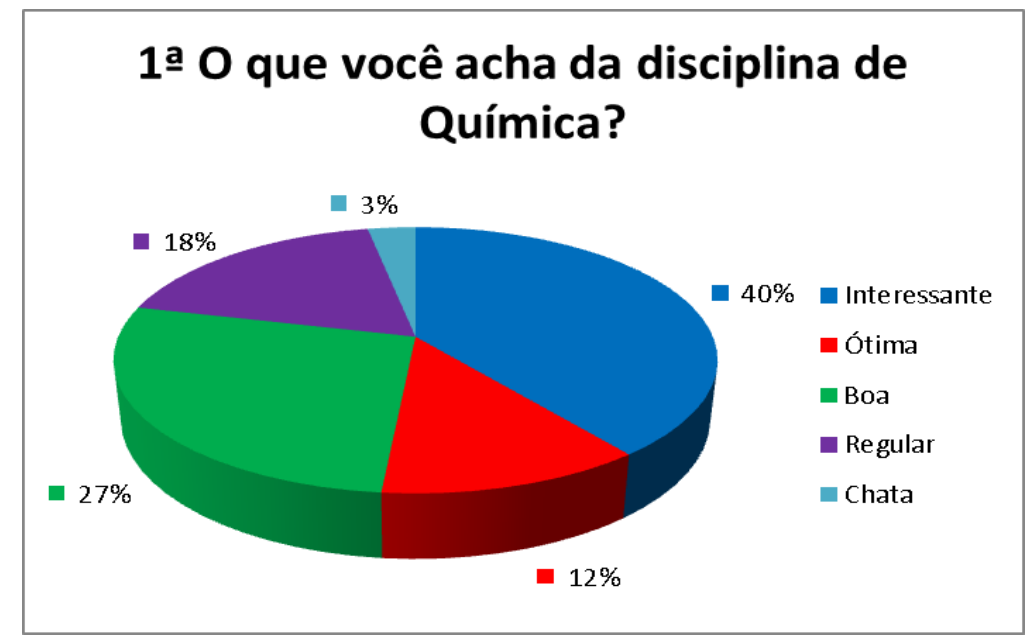

Fonte: Próprio autor

Revista de Pesquisa Interdisciplinar, Cajazeiras, n. 2, suplementar, p. 476-491, set. de 2017. 


\section{PROPEX}

Na $2^{\text {a }}$ questão, Gráfico 02, questionados sobre qual o principal método de avaliação do professor, $44 \%$ responderam que é por meio de trabalhos individuais, 36\% disseram ser por provas escritas e $20 \%$ responderam que é por trabalhos coletivos. Pode-se perceber que os discentes não são avaliados em relação a atividades práticas.

Gráfico 02 - O principal método de avaliação do professor de Química.

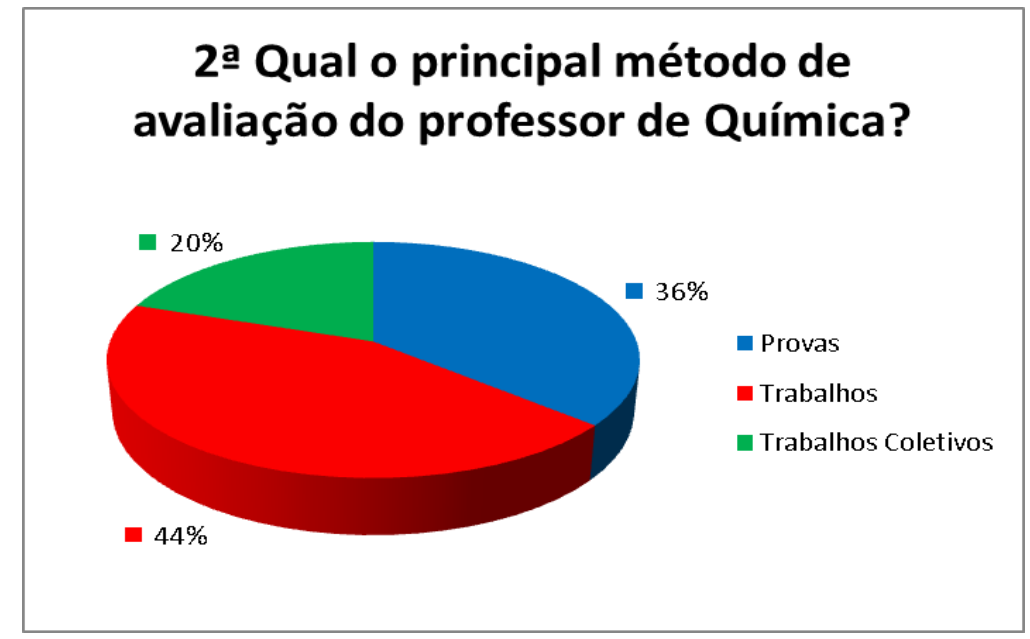

Fonte: Próprio autor

Na $3^{\text {a }}$ questão, Gráfico 03, ao serem indagados que nota daria como avaliação do professor da disciplina de Química com relação a sua forma de ensinar, obteve-se que 39\% consideram nota 10,0 para o professor, $32 \%$ daria a nota 9,0 para o docente, $21 \%$ avaliaram o professor com nota 8,0 e $8 \%$ dos alunos avaliaram o professor com nota 7,0 . A maioria conceituou o docente da disciplina com nota 10,0, ou seja, um conceito muito bom.

Gráfico 03 - Sobre a avaliação da metodologia de ensino do professor.

Revista de Pesquisa Interdisciplinar, Cajazeiras, n. 2, suplementar, p. 476-491, set. de 2017. 


\section{PROPEX}

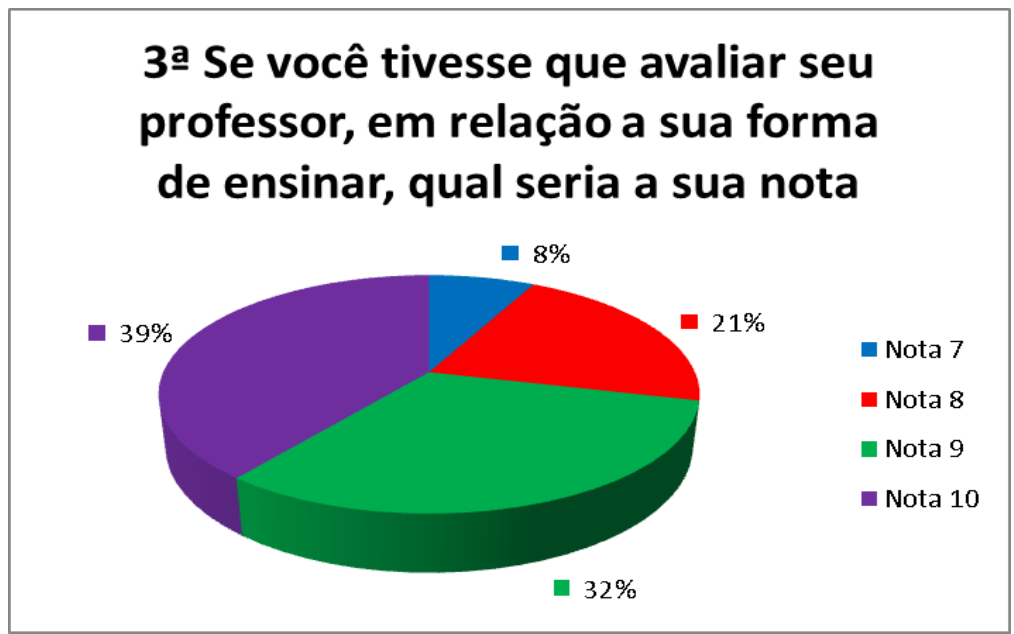

Fonte: Próprio autor

$\mathrm{Na} 4^{\mathrm{a}}$ questão, Gráfico 04, ao responderem qual o tipo de aula utilizada pelo professor de Química, um percentual de 68\% dos alunos respondeu que ele utiliza a aula discursiva, já $23 \%$ disse que é de forma participativa, 5\% afirmou que é de forma experimental e $4 \%$ respondeu de forma expositiva.

Gráfico 04 - Sobre o tipo de aula utilizada pelo professor.

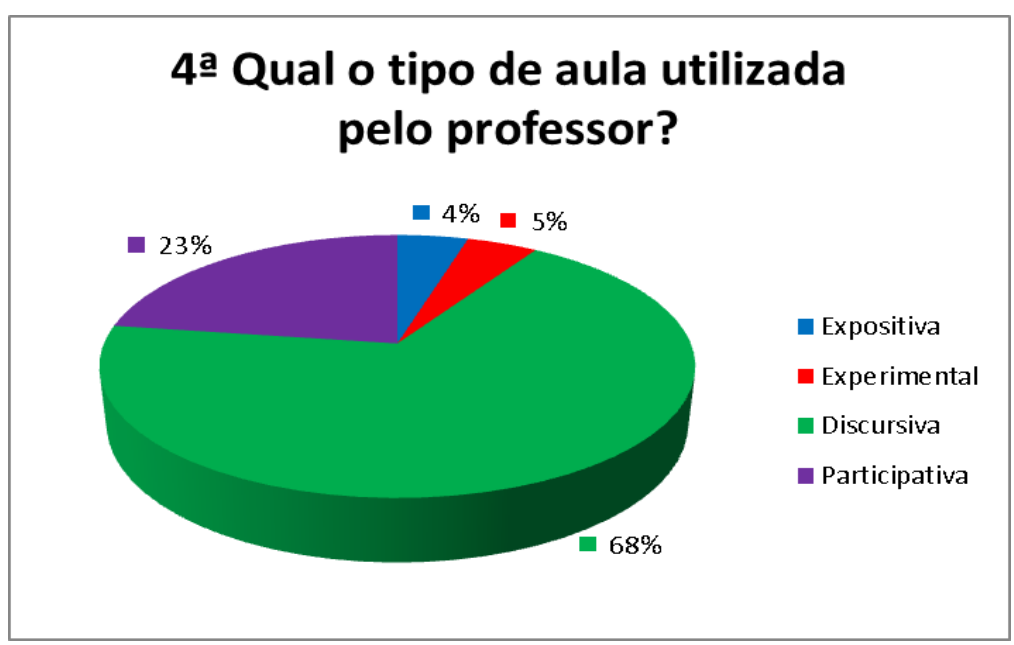

Fonte: Próprio autor

Ao responderem a $5^{\mathrm{a}}$ questão, Gráfico 05 , sobre a sua compreensão do conteúdo após a explicação do professor, apenas $39 \%$ considerou que tem uma boa compreensão, $29 \%$ falou 


\section{PROPEX}

que a compreensão é regular, $26 \%$ considera ótima, $5 \%$ considera ruim e apenas $1 \%$ destes afirmam que tem uma compreensão excelente.

Gráfico 05 - Quanto à compreensão do conteúdo após a explicação do professor.

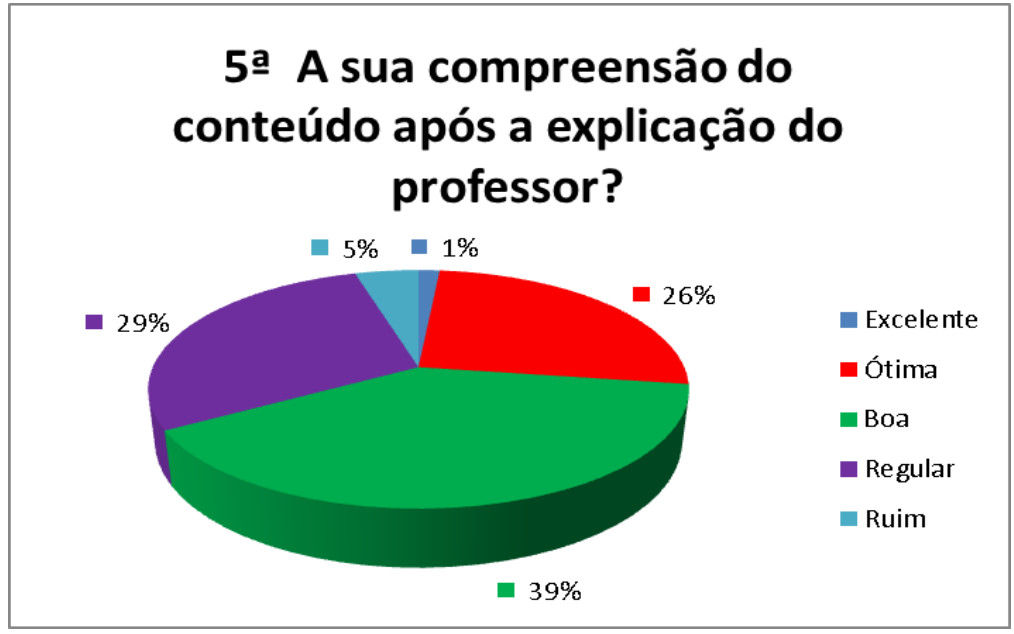

Fonte: Próprio autor

$\mathrm{Na} 6^{\mathrm{a}}$ questão, Gráfico 06, perguntou-se com que frequência o professor utiliza aulas práticas, 64\% responderam que raramente o professor utiliza essa metodologia, já 30\% afirmou que às vezes o professor utiliza e $6 \%$ respondeu que é sempre utilizada.

Gráfico 06 - A frequência que o professor utiliza aula prática.

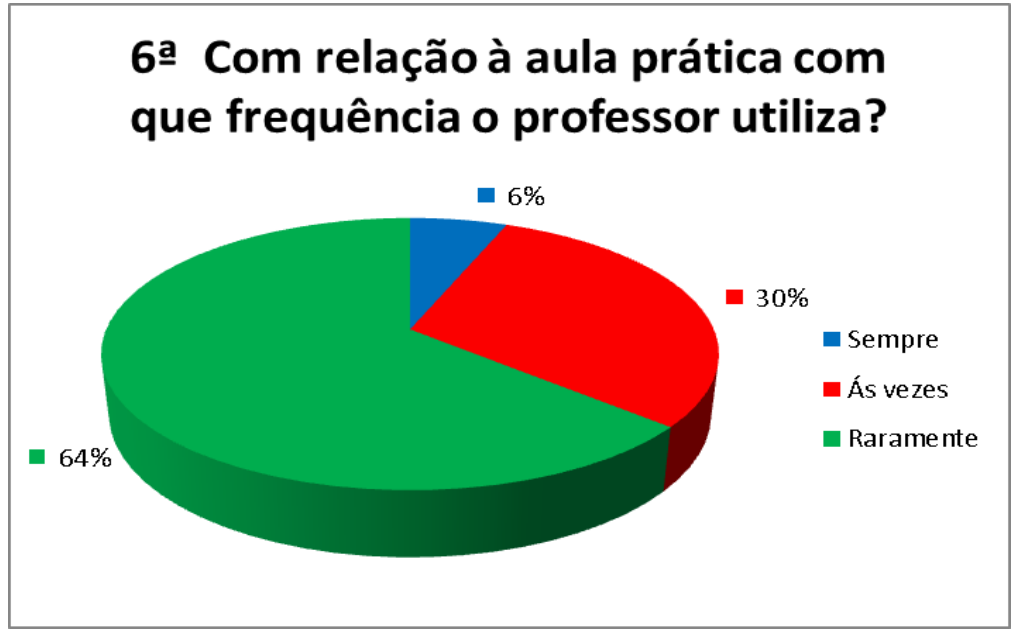

Fonte: Próprio autor 


\section{PROPEX}

A $7^{\mathrm{a}}$ questão, Gráfico 07, pergunta se eles gostariam que houvesse mais aulas práticas, onde a maioria, ou seja, 94\% dos alunos responderam que sim e apenas $6 \%$ destes responderam que não preferiam mais aulas práticas de química.

Gráfico 07 - Sobre a preferência por mais aulas práticas.

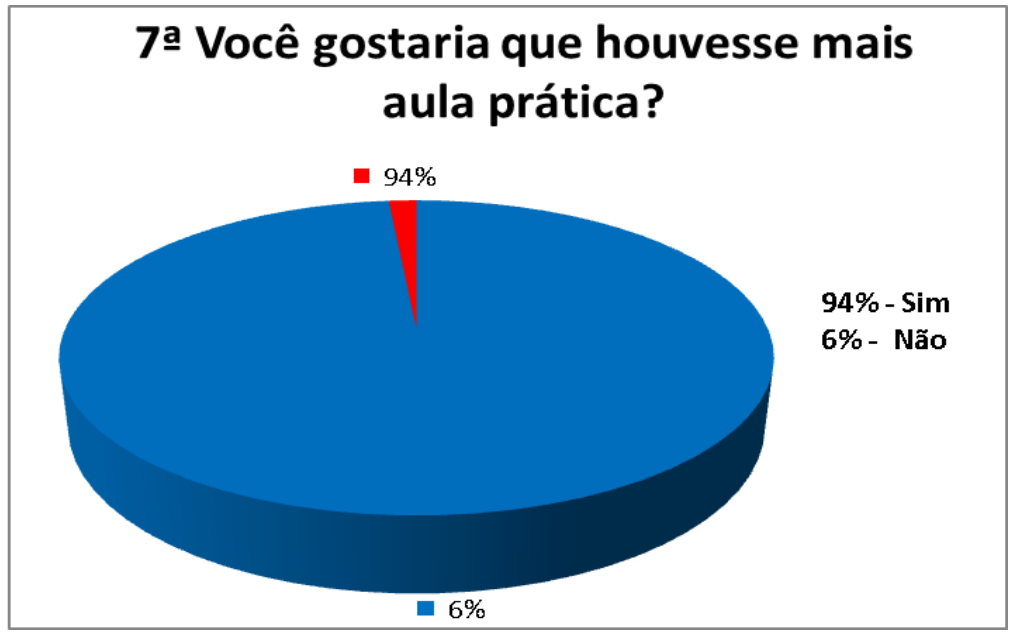

Fonte: Próprio autor

$\mathrm{Na} 8^{\mathrm{a}}$ e última questão, Gráfico 08 , foi solicitado aos discentes que estes sugerissem melhorias no ensino de Química na escola em que estudam. 56\% dos alunos pediram mais aulas práticas, $18 \%$ considera que para melhorar o professor deve mudar a sua metodologia de ensino, para $12 \%$ a didática de ensino deve ser mais específica e surpreendentemente, $8 \%$ considera que é preciso haver mais aulas de Química na grade curricular e 6\% dos discentes sugeriu mais uso de recursos tecnológicos nas aulas.

Gráfico 08 - Sugestão para a melhoria do ensino de Química na instituição de ensino. 


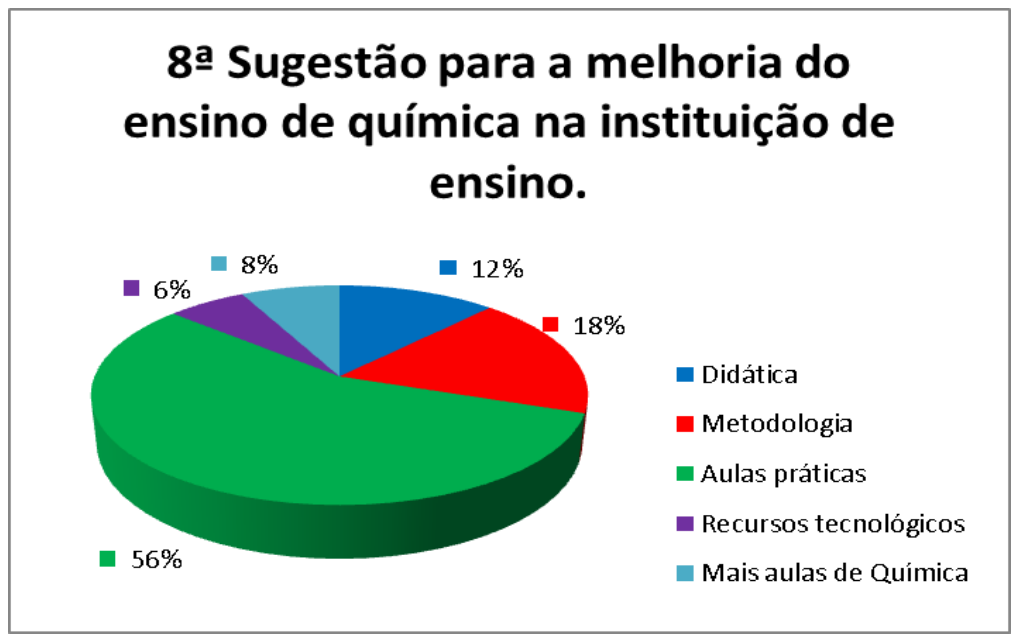

Fonte: Próprio autor

\section{CONSIDERAÇÕES FINAIS}

Com o crescimento vultoso da gama de recursos tecnológicos em todos os âmbitos, sobretudo o de comunicação, o professor de Química contemporâneo tem a necessidade de transformar as aulas somente expositivas com as quais está mais habituado a trabalhar em sala de aula, para desenvolver aulas mais interativas, fomentadas por recursos tecnológicos os quais auxiliem num aprendizado significativo. E aliados a estes, está o uso de práticas laboratoriais, que também podem ser demonstradas ou realizadas, através de simuladores virtuais e o uso de materiais alternativos, quando da falta ou precariedade de laboratório de ciências na instituição de ensino.

A presente pesquisa demostra o quanto os discentes estão e se sentem atraídos por aulas diferenciadas da somente tradicional teoria.

Conforme o que foi observado nas questões ênfase deste estudo, um percentual de 94\% dos estudantes gostaria de mais aulas práticas de Química e 56\% destes discentes sugerem mais aulas práticas no ensino de Química como melhoria no ensino da disciplina em sua instituição.

Portanto fica evidenciado nos resultados deste estudo, a importância da aula prática de Química, podendo esse método ser aplicado não somente em laboratório de ciências, mas também com materiais alternativos ou através de simuladores virtuais. 


\section{REFERÊNCIAS BIBLIOGRÁFICAS}

BRASIL, Secretaria de Educação Média e Tecnológica. PCNs+ Ensino Médio: orientações educacionais complementares aos Parâmetros Curriculares Nacionais. Ciências da Natureza, Matemática e suas Tecnologias. Brasília: MEC, SEMTEC, 2002. 144p.

FERREIRA, Maricélia Lucena; SILVA, Egle Katarinne Souza; SALES, Luciano Leal de Morais. Contribuições Através da Experimentação Para Promoção do Ensino de Química. In: CONGRESSO NACIONAL DE EDUCAÇÃO, 2., 2015, Campina Grande. Anais... Campina Grande, Realize, 2015, v. 1.

GUIMARÃES, C. C. Experimentação no Ensino de Química: Caminhos e Descaminhos Rumo à Aprendizagem Significativa. Química Nova na Escola, São Paulo, v. 13, n. ${ }^{\circ}$ 3, p. 198-202, Agosto - 2009. 